\title{
A COMPARATIVE FLOW ANALYSIS OF NACA 6409 AND NACA 4412
}

\section{AEROFOIL}

\author{
MD. Safayet Hossain ${ }^{1}$, Muhammad Ferdous Raiyan ${ }^{2}$, Mohammed Nasir Uddin Akanda ${ }^{3}$, Nahed \\ Hassan Jony ${ }^{4}$ \\ ${ }^{1}$ Department of Mechanical Engineering, CUET, Chittagong, Bangladesh \\ ${ }^{2}$ Department of Mechanical Engineering, CUET, Chittagong, Bangladesh \\ ${ }^{3}$ Department of Electrical Engineering, CUET, Chittagong, Bangladesh \\ ${ }^{4}$ Department of Mechanical Engineering, CUET, Chittagong, Bangladesh
}

\begin{abstract}
In this work, flow analysis of two aerofoils (NACA 6409 and NACA 4412) was investigated. Drag force, lift force as well as the overall pressure distribution over the aerofoils were also analysed. By changing the angle of attack, variation in different properties has been observed. The outcome of this investigation was shown and computed by using ANSYS workbench 14.5. The pressure distributions as well as coefficient of lift to coefficient of drag ratio of these two aerofoils were visualized and compared. From this result, we compared the better aerofoil between these two aerofoils. The whole analysis is solely based on the principle of finite element method and computational fluid dynamics (CFD). Finally, by comparing different properties i.e drag and lift coefficients, pressure distribution over the aerofoils, it was found that NACA 4412 aerofoil is more efficient for practical applications than NACA 6409 aerofoil.
\end{abstract}

Keywords: NACA, Drag Lift, CFD, ANSYS FLUENT, SolidWorks. ****.

\section{INTRODUCTION}

Aerodynamics is a branch of science that deals with the analysis of flow over a body. The rapid evolution of CFD has been driven for faster and accurate method for solving problems related to aerodynamics. The flow of air over the aerofoils is the most important thing that has to be considered during designing an aircraft, missile, sport vehicles or any other aerodynamic objects. Analysing the flow of a compressible fluid is always complex and consists of different terms and characteristics. By using ANSYS, flow analysis becomes more effective as it investigates everything more thoroughly than experimental method.

Computational fluid dynamics provides a qualitative and sometimes even quantitative prediction of fluid flow by means of mathematical modelling, numerical method and software tools. CFD analysis enables an engineer to compute the flow numerically in a 'virtual flow laboratory'. The analysis consists of several steps such as: problem statement, mathematical modelling, mesh generation, space discretization, time discretization, iterative solver, simulation run, post processing, and verification.

ANSYS is vast computational software that enables researchers to analyse the problems related to different engineering sectors. It is used to solve problems related to heat transfer, fluid flow, turbulence, industrial machineries, explicit dynamics, and structural analysis with the assistance of numerical analysis.
Chervonenko [1] showed the effect of attack angle on the non-stationary aerodynamic characteristics and flutter resistance of a grid of bent vibrating compressor blades. Bacha et al. [2] presented drag prediction in transitional flow over two-dimensional aerofoils. Eleni et al. [3] evaluated the turbulence models for the simulation of the flow over NACA 0012 aerofoil. Ramdenee et al. [4] investigated on modelling of aerodynamic flutter on a NACA (National Advisory Committee for Aeronautics) 4412 aerofoil with application to wind turbine blades. Johansen [5] also evaluated laminar/turbulent transition in aerofoil flows. Launder et al. [6] showed the numerical computation of turbulent flows. 2D analysis of NACA 4412 aerofoil was done by Kevadiya et al.[7]. Mentar [8] presented two-equation eddy-viscosity turbulence models for engineering applications. Mashud et al. [9] showed the effect of spoiler position on aerodynamics characteristic of an aerofoil. Gulzar et al. [10] represented the impact of variation in angle of attack in NACA 7420 aerofoil in transonic compressible flow using Spalart-Allmaras turbulence model. . Aerodynamic stall suppression on aerofoil sections using passive air-jet vortex generators were investigated by Prince et al. [11] Shih et al. [12] showed a new k- $\varepsilon$ eddy-viscosity model for high Reynolds number turbulent flows. Bensiger et al. [13] analysed a bi convex aerofoil by using CFD at supersonic and hypersonic speed. Sutherland W [14] evaluated the viscosity of gases and molecular force.

Aerofoils and aerodynamic shaped objects are extensively used in all types of air vehicles for example space shuttle, aircrafts, helicopters and even in various types of missiles. 
Besides, when it comes to fluid machineries such as pump, turbine, windmill, the shape of impeller, propeller is very important. All the parameters which are important to express the characteristics of aerofoils must be inspected with high precision. That's why analysis of flow over aerofoils is very important.

In this investigation, pressure distribution was analysed along with coefficient of lift and coefficient of drag of two particular NACA aerofoils. Later, coefficient of lift to coefficient of drag ratio was compared between these aerofoils to find out the more practical one.

\section{THEORETICAL ANALYSIS}

The force which is exerted on a body by a flowing fluid in the direction of flow is called drag. The component of this force normal to the body is called lift force. If pressure and shear forces acting on a differential area of $d A$ on a surface is $P d A$ and $\tau d A$ respectively, the differential drag and lift forces acting on $\mathrm{dA}$ are

$$
\begin{aligned}
& d F_{D}=-P d A \cos \theta+\tau d A \sin \theta \\
& d F_{L}=-P d A \sin \theta-\tau d A \cos \theta
\end{aligned}
$$

Now the drag force is,

$$
F_{D}=\int d F_{D}=\int(-P \cos \theta+\tau \sin \theta) d A
$$

And lift force is,

$$
F_{L}=\int d F_{L}=-\int(P \sin \theta+\tau \cos \theta) d A
$$

Drag force and lift force can also be written by using coefficient of drag and co-efficient of lift respectively.

$$
\begin{aligned}
& F_{D}=\frac{1}{2} \rho A V^{2} C_{D} \\
& F_{L}=\frac{1}{2} \rho A V^{2} C_{L}
\end{aligned}
$$

Besides, the lift phenomenon can also be explained by using Bernoulli's equation. According to Bernoulli's equation, for an incompressible steady state flow, pressure increases if the flow velocity decreases and vice versa. When the air passes over the aerofoil, velocity increases as the air continues to flow from its leading edge to the upper surface of the aerofoil. The pressure is decreased in that area. But on the other hand, velocity decreases as the air passes through the bottom of the aerofoil and the pressure is increased. This positive pressure acting upward acts as the key ingredient for generating lift.

When a fluid separates from a body, it forms a separated region between the body and the fluid stream. This low pressure region behind the body where recirculation and backflows occur is called the separated region. The larger the separated region, the larger the drag force. Wake can be defined as a region of flow trailing the body where the effects of the body on velocity are felt. Wake consists of vortices which are responsible for creating drag by creating negative pressure in that region. Wake doesn't occur only in bluff bodies. Wake can occur in an aerodynamic body with a relatively large angle of attack (larger than 15 degree for most aerofoils). This is known as stalling point. Negative pressure and drag force become dominant from stalling point.

Separation of boundary layer depends on Reynolds number. For higher values of Reynolds number, it exhibits an early transition from laminar to turbulent flow. The higher the Reynolds number, there will be greater tendency that the flow is turbulent.

Reynolds number $R_{e}$ is defined by,

$$
R_{e}=\frac{\rho U x}{\mu}
$$

Here $\mathrm{x}$ is the thickness of boundary layer where the transition from laminar to turbulent starts.

For analysing the pressure distribution over the aerofoil with pressure $\mathrm{p}$ and boundary layer thickness $\mathrm{x}$, Navier-Stokes equation is used which can be defined as,

$$
\frac{\partial u}{\partial t}+u \frac{\partial u}{\partial x}=-\frac{1}{\rho} \frac{d P}{d x}
$$

For steady flow, the pressure $\mathrm{p}$ is the function of $\mathrm{x}$ only, the partial derivative $\frac{\partial p}{\partial x}$ may, therefore, be replaced by the total derivative $\frac{d p}{d x}$ and Eq. (8) can be expressed in the following form,

$$
u \frac{\partial u}{\partial x}=-\frac{1}{\rho} \frac{\partial p}{\partial x}
$$

By integrating,

$$
p+\frac{1}{2} \rho U^{2}=\text { constant }
$$

Finally, the simplified Navier-Stokes equation maybe written as,

$$
\frac{\partial u}{\partial t}+u \frac{\partial u}{\partial x}+v \frac{\partial u}{\partial y}=-\frac{1}{\rho} \frac{\partial p}{\partial x}+v \frac{\partial^{2} u}{\partial y^{2}}
$$

Combining Eq. (9) and Eq. (11), the steady flow equation can be written as,

$$
u \frac{\partial u}{\partial x}+v \frac{\partial u}{\partial y}=U \frac{\partial u}{\partial x}+v \frac{\partial^{2} u}{\partial y^{2}}
$$

And the continuity equation for the two-dimensional steady flow is

$$
\frac{\partial u}{\partial x}+\frac{\partial u}{\partial y}=0
$$

Eq.(12) and Eq.(13) are known as the Prandtl's boundary layer equation. 
Although the above equation is meant for rectilinear flow, they are applicable to curved flow too.

\section{ANALYTICAL METHOD}

In this process, the chosen aerofoils were generated by using an online aerofoil generator [15] from which the coordinates were imported to create the geometry of those aerofoils. After obtaining the co-ordinates, they were imported to SolidWorks 2013 for creating the desired geometry. The 2D view of these aerofoils was shown in Fig. 1 and 2 respectively. The CFD analysis of these aerofoils was done by ANSYS.

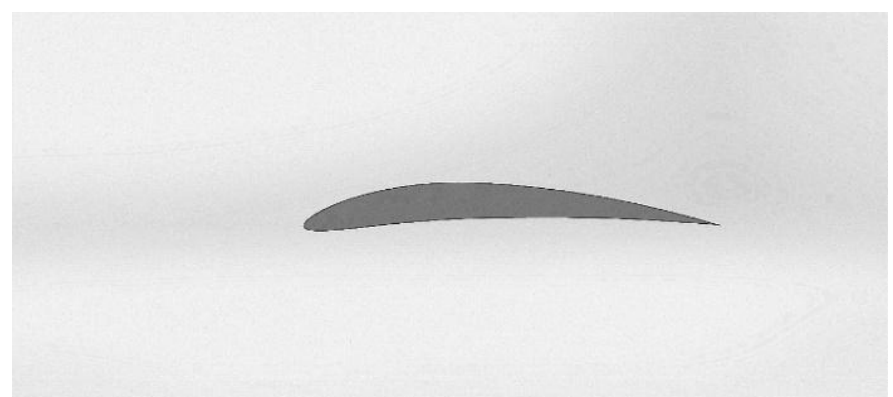

Fig- 1: 2D view of NACA 6409 aerofoil.

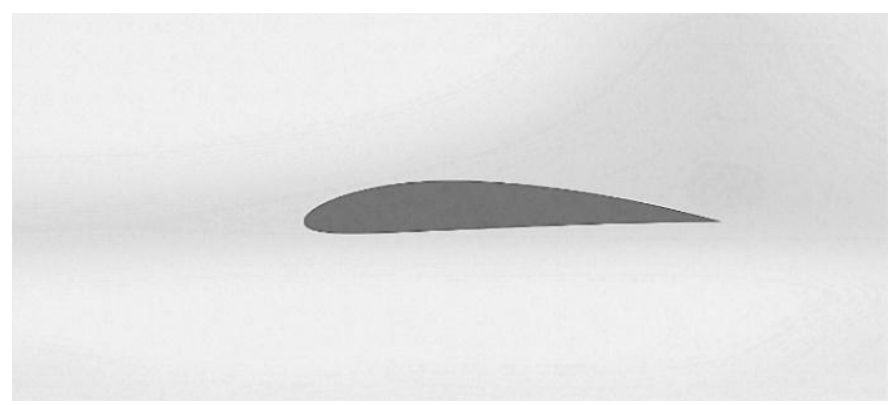

Fig- 2: 2D view of NACA 4412 aerofoil.

\subsection{NACA 6409 Aerofoil Analysis}

The mesh was generated at the beginning according to Fig. 3 and 4 respectively. This meshing process and principle are based on the theory of finite element analysis method.

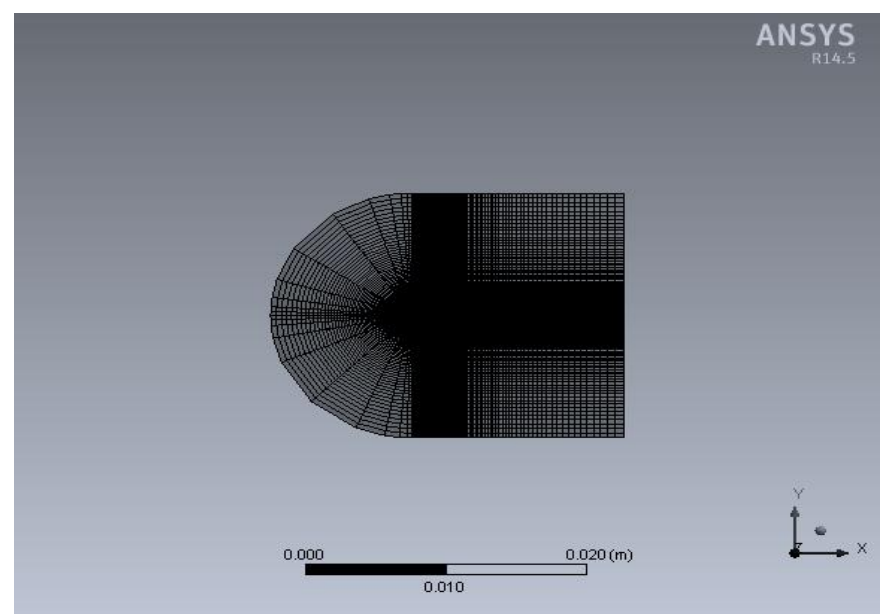

Fig- 3: Complete mesh generation of NACA 6409 aerofoil.
Here, the surrounding area of aerofoil was divided into tiny elements in order to facilitate the numerical analysis based on finite element method.

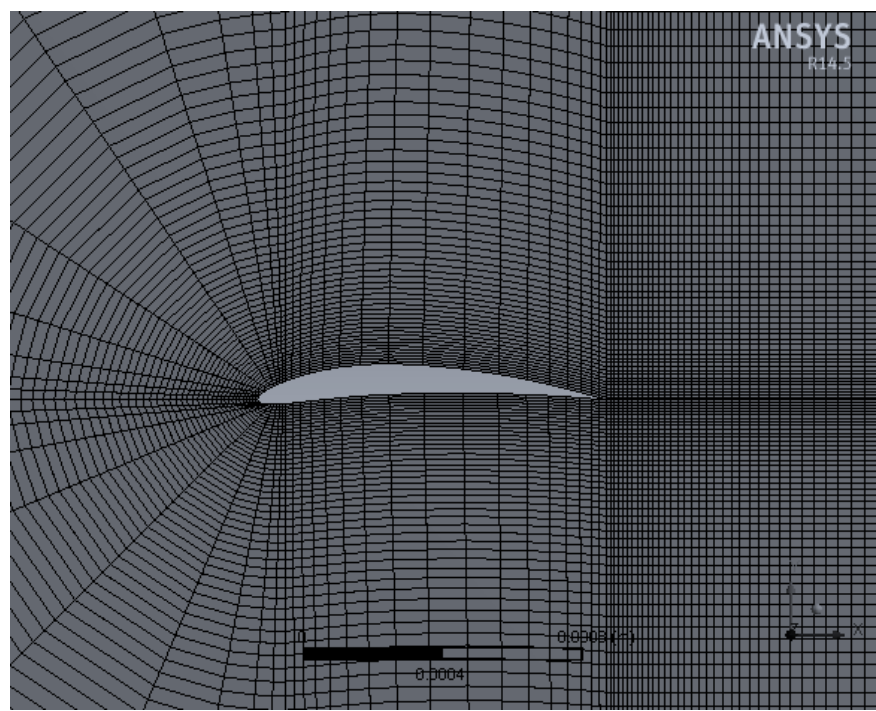

Fig- 4: Enlarged view of generated mesh.

Analysis began after the visualization of the output from the simulation process. As the simulation process was very lengthy, the number of nodes was set at 25755 and elements at 25500 . Accuracy depends on the number of elements and nodes. The result would be more specific and accurate if the number of nodes and elements could be increased in the mesh. But it was set around 25000 for reducing the tardiness and complexities of simulation. With the increase in number of nodes and elements, the finite element analysis can be performed more accurately. The input values at the beginning of simulation were set according to the values of Table 1 given below.

Table- 1: Initial values for NACA 6409 aerofoil

\begin{tabular}{|l|l|}
\hline Number of elements in mesh & 25500 \\
\hline Number of nodes in the mesh & 25755 \\
\hline $\begin{array}{l}\text { Number of iterations for } \\
\text { generating mesh }\end{array}$ & 500 \\
\hline Model & Viscous laminar \\
\hline Laminar flow velocity & $1 \mathrm{~m} \mathrm{~s}^{-1}$ \\
\hline Air density & $1.225 \mathrm{~kg} \mathrm{~m}^{-3}$ \\
\hline Viscosity & $1.7894 \mathrm{e}^{-05} \mathrm{~kg} \mathrm{~s} \mathrm{~m}^{-2}$ \\
\hline
\end{tabular}




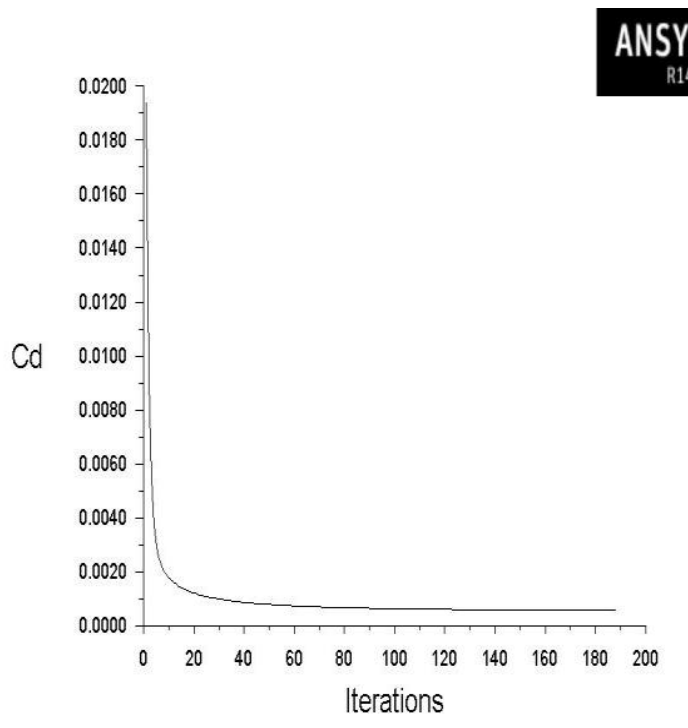

Add-1 Convergence History 14, 2014
ANSYS Fluent 14.5 (2d, dp, pbns, lam)

Fig-: 5 Coefficient of drag for 0 degree angle of attack for NACA 6409.

ANSYS

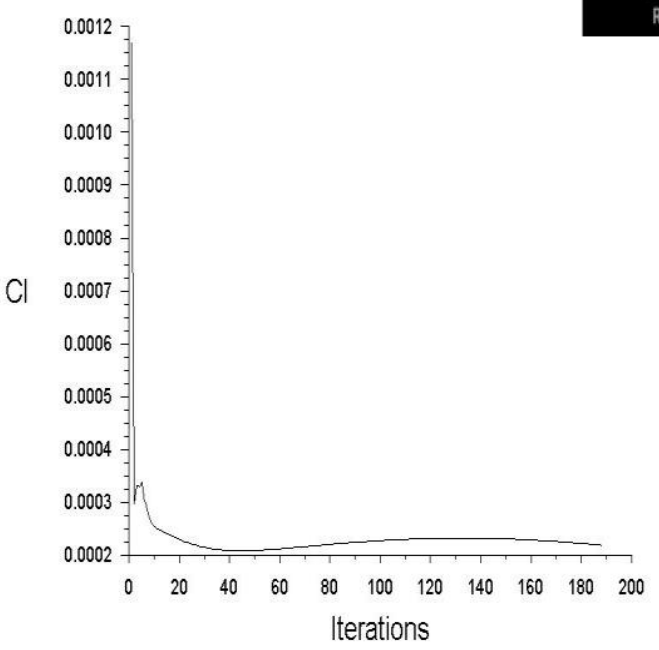

Cl-1 Convergence History
ANSYS Fluent 14.5 (2d, dp, pbns, lam)

Fig- 6: Coefficient of lift for 0 degree angle of attack for NACA 6409.

Coefficients of lift and drag were plotted in Fig. 5 and 6 as the number of iterations were going on until it reached to a steady value. After $188^{\text {th }}$ iterations, convergence was obtained and the values of $C_{L}$ and $C_{D}$ as $2.1854 \mathrm{e}^{-04}$ and $5.6133 \mathrm{e}^{-04}$ were found respectively. Convergence history showed that these obtained graphs became more accurate as the number of iterations increased. At the initial stage, the coefficient values were changing with the increase of iteration. After certain iterations (500), the values became steady and were not changing with the number of iterations.

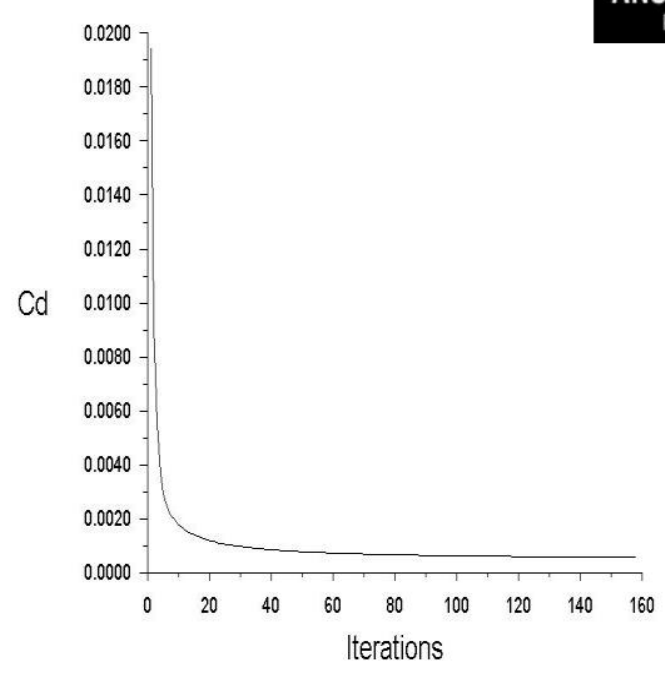

cd-1 Convergence History

Apr 14, 2014 ANSYS Fluent 14.5 (2d, dp, pbns, lam)

Fig- 7: Coefficient of drag for 5 degree angle of attack for NACA 6409.

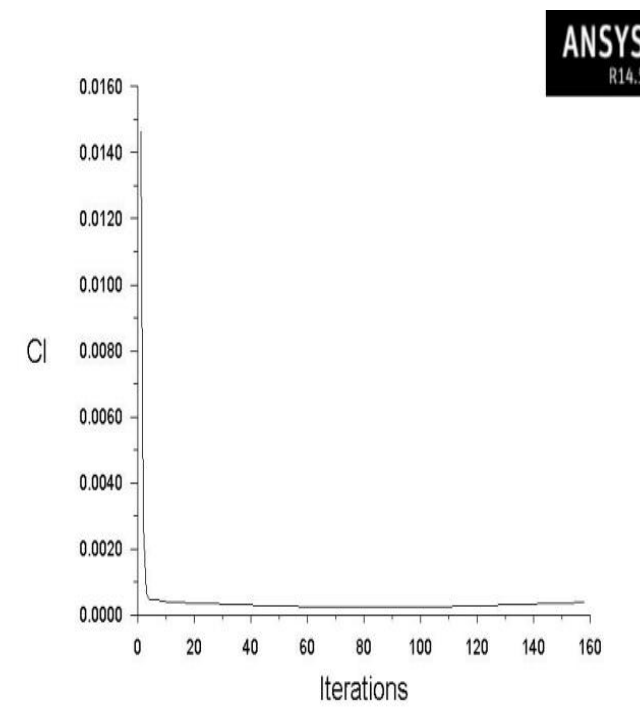

ch-1 Convergence History ANSYS Fluent 145 (20, 14, 2014

Fig- 8: Coefficient of lift for 5 degree angle of attack for NACA 6409.

Like the previous one, coefficient of lift and drag were plotted in Fig. 7 and 8 as the number of iteration was going on until it reached to a steady value. After $158^{\text {th }}$ iterations, convergence was obtained and the values of $C_{L}$ and $C_{D}$ as $3.7830 \mathrm{e}^{-04}$ and $5.6594 \mathrm{e}^{-04}$ were found respectively. As the iteration process continued, the value of $\mathrm{C}_{\mathrm{L}}$ became more stable and accurate and stable. 


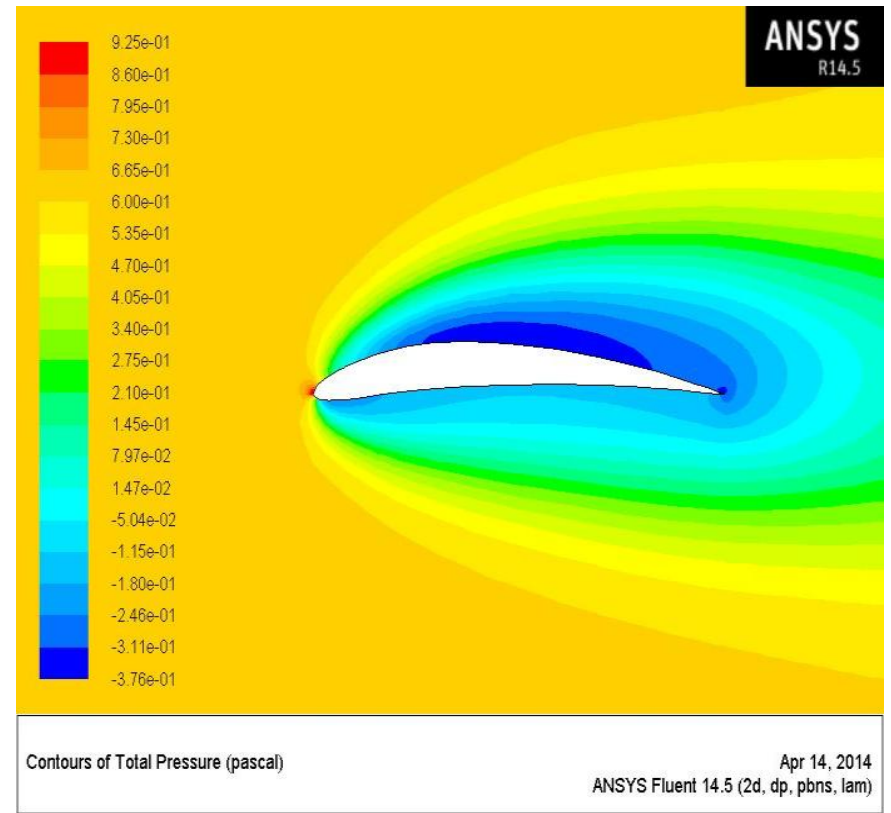

Fig- 9: Total pressure distribution over NACA 6409 aerofoil for an angle of attack 0 degree.

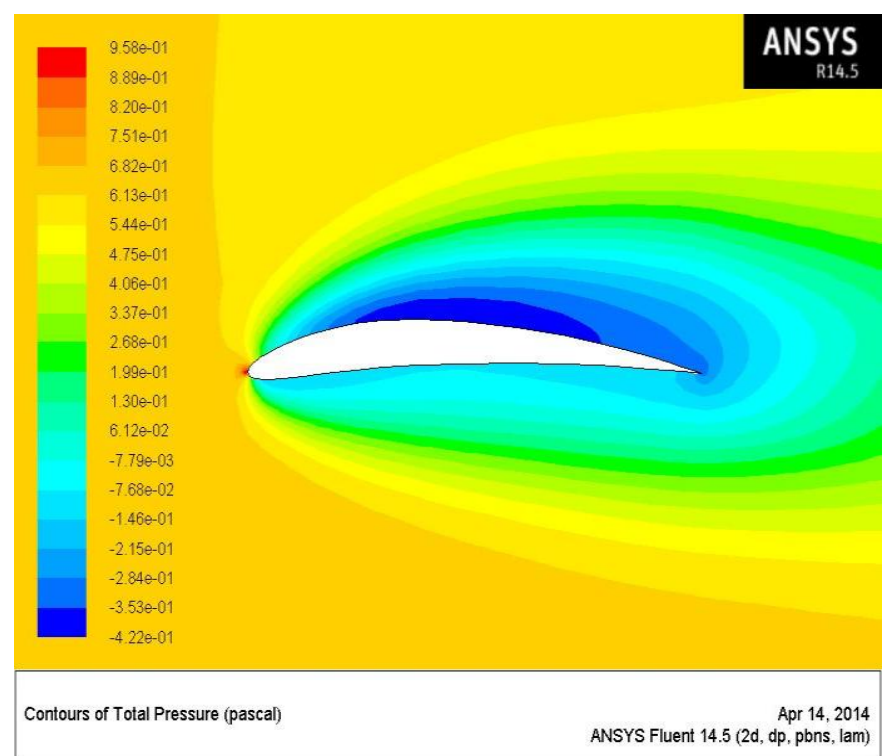

Fig-10: Total pressure distribution over NACA 6409 aerofoil for an angle of attack 5 degree.

From simulation, coefficient of drag and coefficient of lift were found for different angle of attack. Finally the ratio of $C_{L}$ to $C_{D}$ was calculated. In Fig. 9 and 10 , the pressure distribution over the aerofoil is shown. It is also seen from both Fig. 9 and 10 that negative pressure was created on the upper end surface of the aerofoil and simultaneously positive pressure at the lower surface thus generating lift. As the flow passed over the aerofoil, separation started to occur at the trailing edge thus creating wake with negative pressure at that region. With the increase in angle of attack, the lift also began to increase. But it should be noted that lift continues to increase with angle of attack up to a certain point. After that point, with the increase of angle of attack, lift continues to decrease and drag increases.

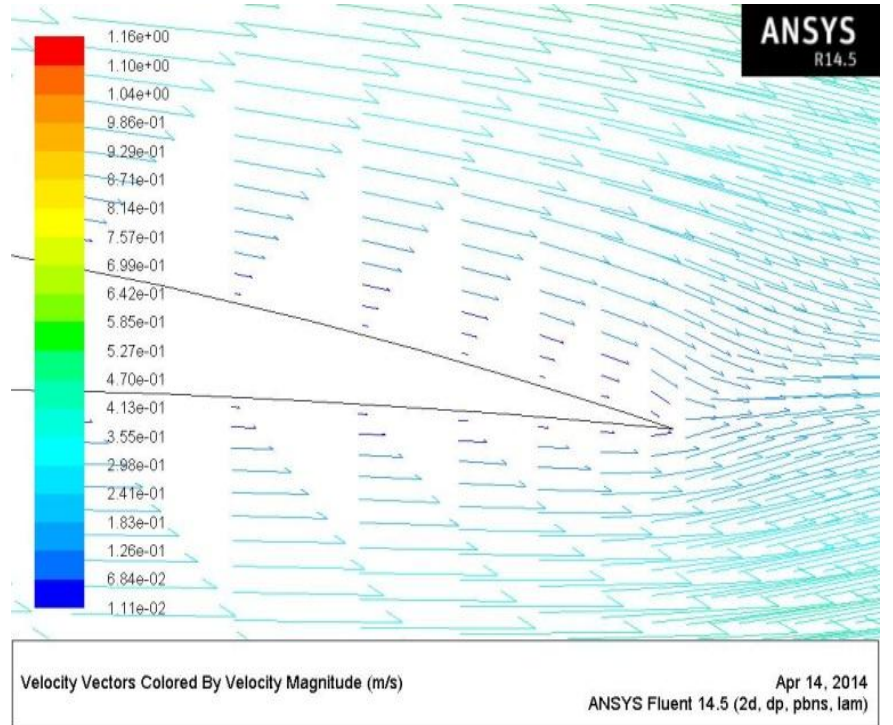

Fig- 11: Vector profile at the trailing edge of NACA 6409 air foil for an angle of attack of 0 degree.

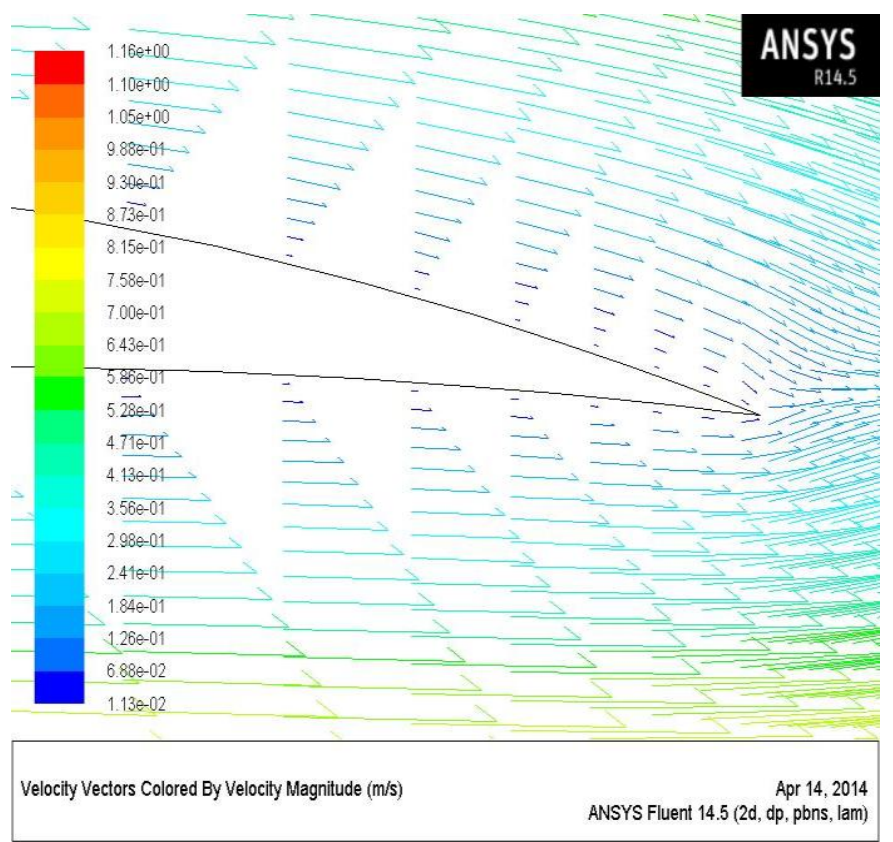

Fig- 12: Vector profile at the trailing edge of NACA 6409 aerofoil for an angle of attack of 5 degree.

Now, in Fig. 11 and 12, we can see the vector profile over the aerofoil body. The streamlines started to detach from the upper surface as the air passed over the lower end of the aerofoil. This is the region where small vortices are created and thus it creates a small amount of negative pressure. These vortices and negative pressure consequently induced wakes near the separation point of the streamlines over the aerofoil.

All the aerofoils used in aerodynamics applications must produce larger amount lift with least amount of drag to exhibit better performance. It is necessary to compare among different aerofoils to find out the most effective one. Therefore, a measure of performance for aerofoils is the liftto-drag ratio which is equivalent to the ratio of the lift and 
drag coefficients. In other words, lift to drag coefficient is the mean of performance for aerofoils. This information can also be obtained by plotting $\mathrm{C}_{\mathrm{L}}$ and $\mathrm{C}_{\mathrm{D}}$ versus different angle of attack. As the lift-to-drag ratio increases with the increase of angle of attack, it was found from simulation that the ratio was also increased for an increase in angle of attack. Lift to drag ratio is a performance parameter for aerofoils. This is typically one of the major goals in aircraft designs. Coefficient of lift and coefficient of drag for NACA 6409 aerofoil are listed in the following table.

Table- 2: Coefficient of drag and lift for different angle of

\begin{tabular}{|c|c|c|}
\hline $\begin{array}{l}\text { Angle of } \\
\text { attack }(\alpha)\end{array}$ & $\begin{array}{l}\text { Coefficient of drag } \\
\left(C_{D}\right)\end{array}$ & $\begin{array}{l}\text { Coefficient of lift } \\
\left(\mathrm{C}_{\mathrm{L}}\right)\end{array}$ \\
\hline 0 & $5.6133 \mathrm{e}^{-04}$ & $2.1854 \mathrm{e}^{-04}$ \\
\hline 5 & $5.6594 \mathrm{e}^{-04}$ & $3.7830 \mathrm{e}^{-04}$ \\
\hline
\end{tabular}

Table- 3: Coefficient of lift to drag ratio for different angle of attack.

\begin{tabular}{|l|l|}
\hline Angle of attack & $\mathrm{C}_{\mathrm{L}} / \mathrm{C}_{\mathrm{D}}$ \\
\hline 0 & 0.39 \\
\hline 5 & 0.66 \\
\hline
\end{tabular}

\subsection{NACA 4412 Aerofoil Analysis}

The following section discussed about the analysis for the NACA 4412 aerofoil. It should be noted that same calculation and theoretical knowledge is applicable for NACA 4412 like the previously discussed NACA 6409 aerofoil. The mesh generation was shown in Fig. 12 and 13 respectively.

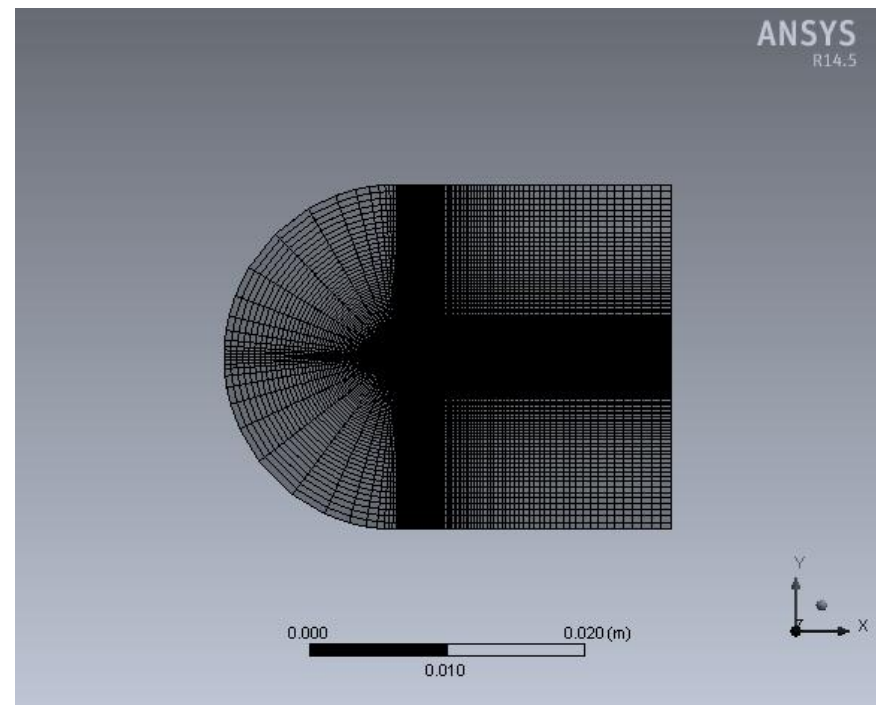

Fig-13: Complete mesh generation of NACA 4412 aerofoil.

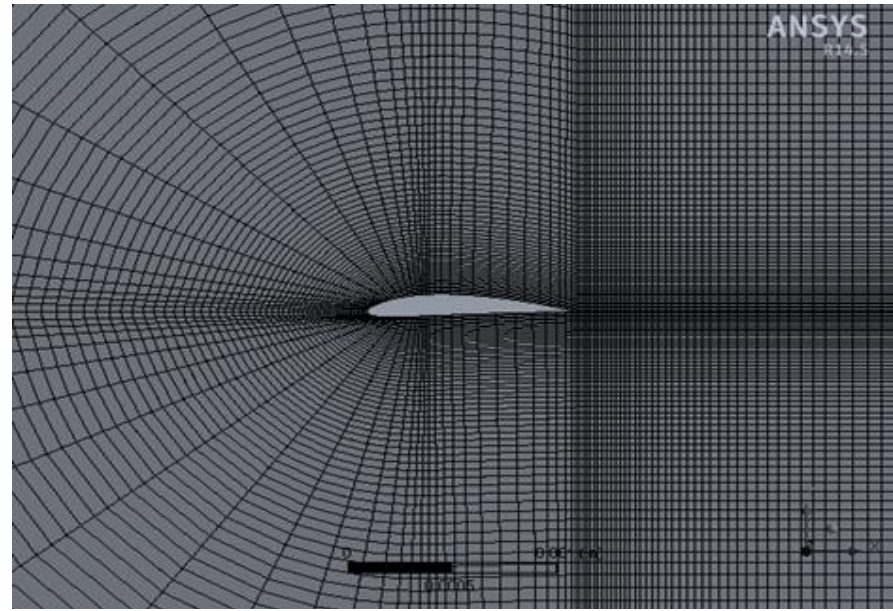

Fig- 14: Enlarged view of generated mesh

After completing the simulation, the output was visualized. In this case, the number of nodes was set at 26462 and elements 26200. Accuracy depended on the number of elements and nodes. The result would be more specific and accurate if the number of nodes and elements could be increased in the mesh. But it was set around 26000 for reducing the tardiness and complexities of simulation. With the increase of number in nodes and elements, the finite element analysis is performed more accurately. The input values at the beginning of simulation were set according to the values of Table 4 given below.

Table- 4: Initial values set for NACA 4412 aerofoil

\begin{tabular}{|l|l|}
\hline Number of elements in mesh & 26200 \\
\hline Number of nodes in the mesh & 26462 \\
\hline $\begin{array}{l}\text { Number of iterations for } \\
\text { generating mesh }\end{array}$ & 500 \\
\hline Model & Viscous laminar \\
\hline Laminar flow velocity & $1 \mathrm{~m} \mathrm{~s}^{-1}$ \\
\hline Air density & $1.225 \mathrm{~kg} \mathrm{~m}^{-3}$ \\
\hline Viscosity & $1.7894 \mathrm{e}^{-05} \mathrm{~kg} \mathrm{~s} \mathrm{~m}^{-2}$ \\
\hline
\end{tabular}

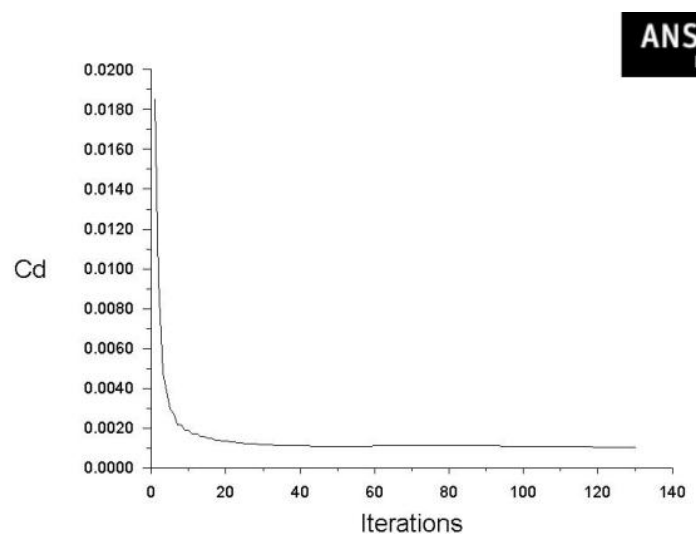

cd-1 Convergence History ANSYS Fluent 14.5 Apr 14, 2014

Fig- 15: Coefficient of drag for 0 degree angle of attack for NACA 4412 


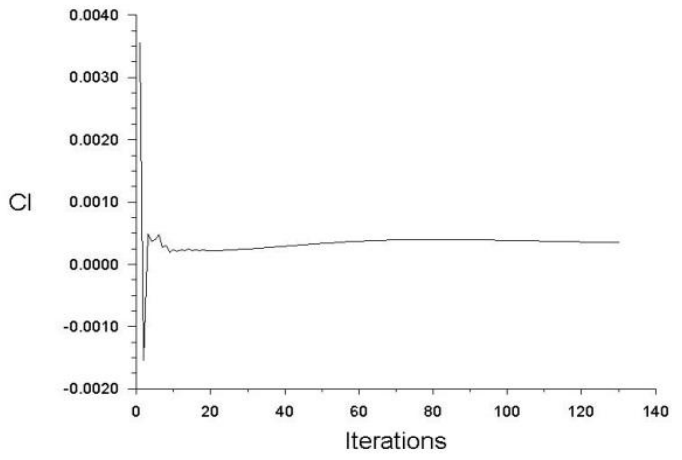

c1-1 Convergence History

Fig- 16: Coefficient of lift for 0 degree angle of attack for NACA 4412

After $130^{\text {th }}$ iterations, convergence was obtained and the values of $C_{L}$ and $C_{D}$ were found as $3.47274 \mathrm{e}^{-04}$ and $1.0318 \mathrm{e}^{-}$ ${ }^{04}$ respectively for 0 degree angle of attack. It is seen from Fig. 15 and16 and also from convergence history that the obtained graph is more accurate as the number of iterations increases.

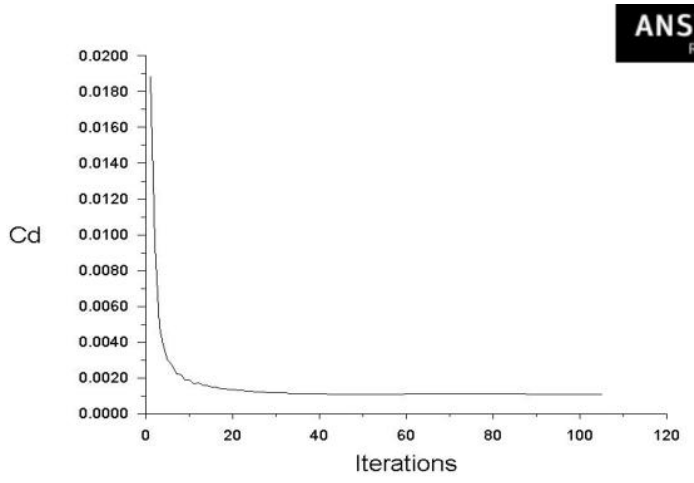

cd-1 Convergence History Apr 14, 2014
ANSYS Fluent 14.5 (2d, dp. pbns, lam)

Fig- 17: Coefficient of drag for 5 degree angle of attack for NACA 4412

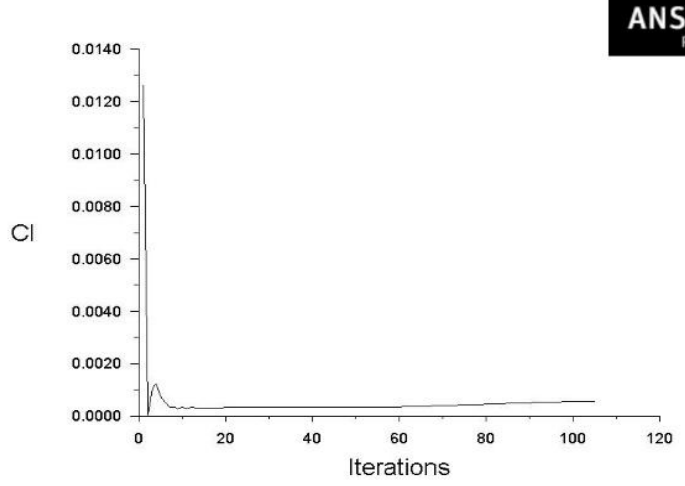

cl-1 Convergence History Apr 14, 2014

Fig- 18: Coefficient of lift for 5 degree angle of attack for NACA 4412
From Fig. 17 and 18, after $105^{\text {th }}$ iterations, convergence is obtained and the values of $C_{L}$ and $C_{D}$ were $5.7556 \mathrm{e}^{-04}$ and $1.0694 \mathrm{e}^{-04}$ respectively for 5 degree angle of attack. As the iteration process continued, the value of $\mathrm{C}_{\mathrm{L}}$ became more stable and accurate.

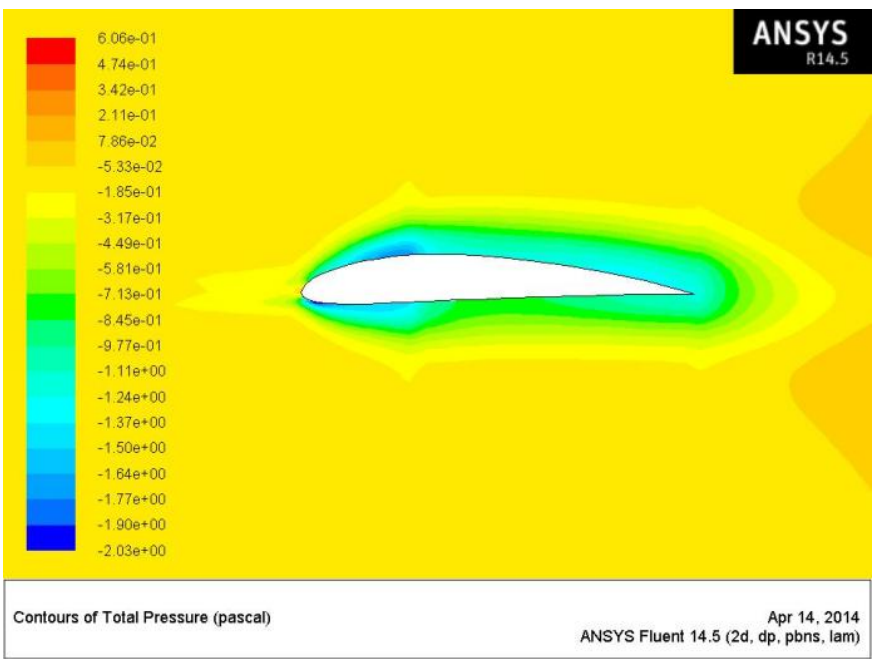

Fig- 19: Total pressure distribution over NACA 4412 aerofoil for an angle of attack 0 degree.

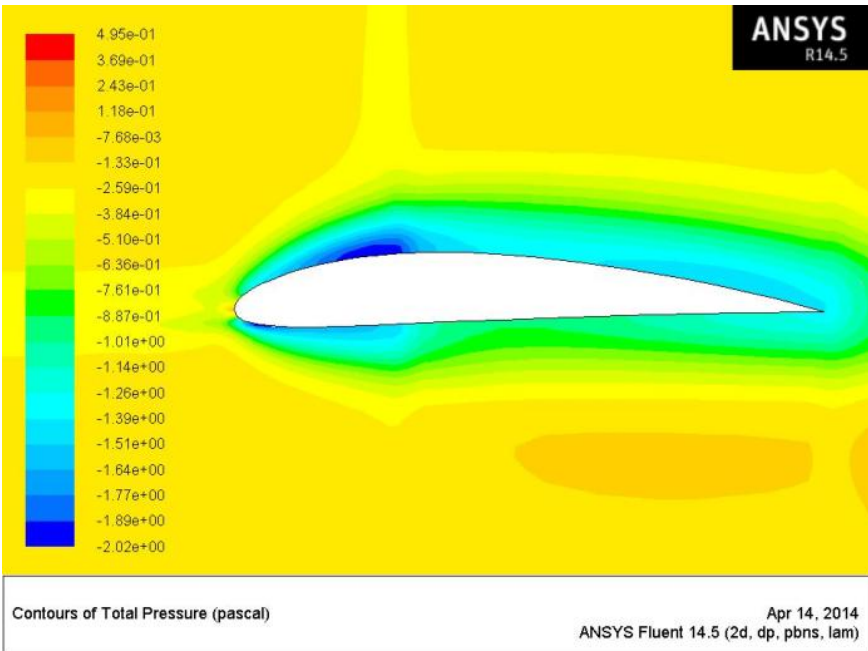

Fig- 20: Total pressure distribution over NACA 4412 aerofoil for an angle of attack 5 degree.

From simulation, coefficient of drag and coefficient of lift for different angle of attack were found. Finally the ratio of $\mathrm{C}_{\mathrm{L}}$ to $\mathrm{C}_{\mathrm{D}}$ was calculated. From the flow visualization, the pressure distribution over the aerofoil was obtained. It can be seen from both Fig. 19 and 20 that negative pressure was created on the upper end surface of the aerofoil and simultaneously positive pressure at the lower surface thus generating lift. As the flow passed over the aerofoil, separation started to occur at the trailing edge thus creating wake with negative pressure at that region. As the angle of attack increased, the lift also begins to increase. 


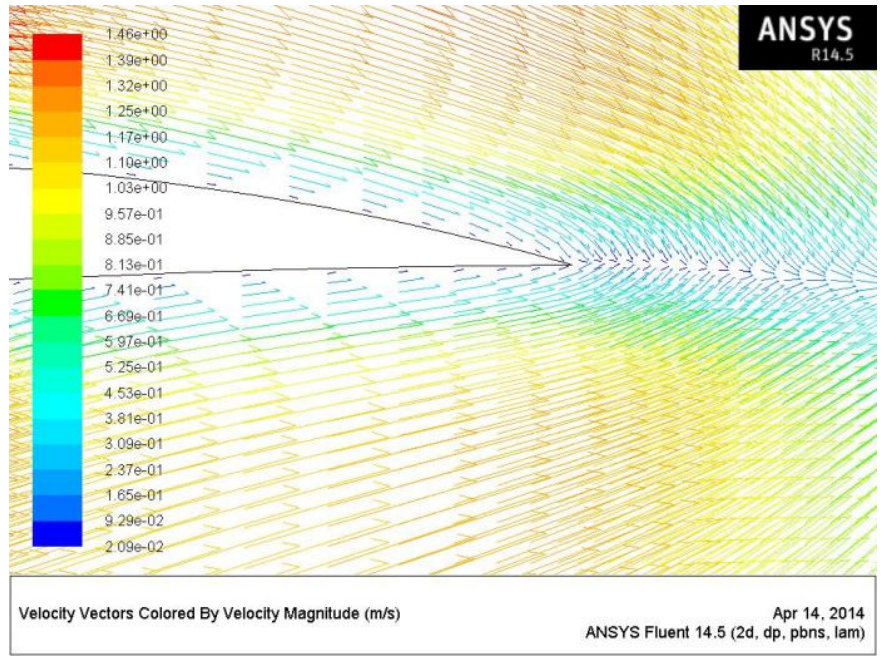

Fig- 21: Vector profile at the trailing edge for NACA 4412 aerofoil for an angle of attack of 0 degree.

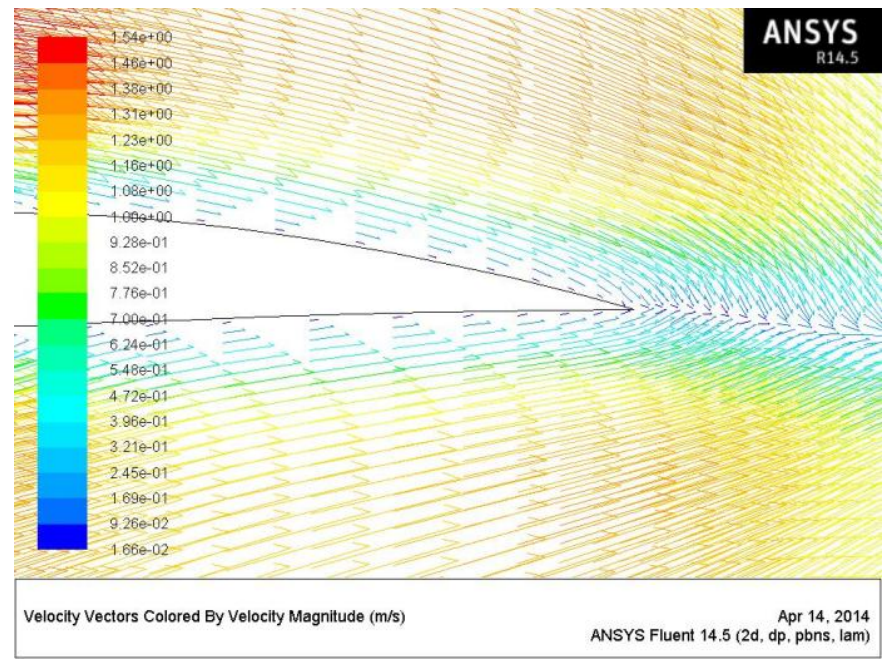

Fig- 22: Vector profile at the trailing edge for NACA 4412 aerofoil for an angle of attack of 5 degree

Now from Fig. 21 and 22, the vector profile over the aerofoil body can be seen. The streamlines started to detach from the upper surface as the air passed over the lower end of the aerofoil. This is the region where small vortices are created and thus creating a small amount of negative pressure. This vortices and negative pressure consequently induced wakes near the separation point of the streamline over the aerofoil.

An important consequence of this periodic generation of vortices downstream is referred as vortex shedding. It is desirable for aerofoils to generate the most amount of lift while producing the least amount of drag. Therefore, a measure of performance for aerofoils is the lift-to-drag ratio which is equivalent to the ratio of the lift and drag coefficients. This information was obtained by plotting $\mathrm{C}_{\mathrm{L}}$ or $\mathrm{C}_{\mathrm{D}}$ versus different angle of attack. As the lift-to-drag ratio increases with the increase of angle of attack, it was also found from simulation that the ratio was increased for an increase in angle of attack. The value of lift-to-drag ratio can be of the order of 100 for a two dimensional aerofoil.
Table-5: Coefficient of lift and drag for different angle of attack

\begin{tabular}{|l|ll|ll|}
\hline $\begin{array}{l}\text { Angle of } \\
\text { attack }(\alpha)\end{array}$ & $\begin{array}{l}\text { Coefficient of drag } \\
\left(\mathrm{C}_{\mathrm{D}}\right)\end{array}$ & $\begin{array}{l}\text { Coefficient of lift } \\
\left(\mathrm{C}_{\mathrm{L}}\right)\end{array}$ \\
\hline 0 & $1.0318 \mathrm{e}^{-04}$ & & $3.47274 \mathrm{e}^{-04}$ & \\
\hline 5 & $1.0694 \mathrm{e}^{-04}$ & & $5.7556 \mathrm{e}^{-04}$ & \\
\hline
\end{tabular}

Table- 6: Coefficient of lift to drag ratio for different angle of attack

\begin{tabular}{|l|l|}
\hline Angle of attack & $\mathrm{C}_{\mathrm{L}} / \mathrm{C}_{\mathrm{D}}$ \\
\hline 0 & 3.365 \\
\hline 5 & 5.382 \\
\hline
\end{tabular}

\section{RESULTS AND DISCUSSION}

The sole purpose of this simulation based experiment was to compare the different parameters of NACA 6409 and NACA 4412 aerofoil and thus finding out which one is the most efficient between these two. It is obvious that there were significant differences among various properties of these two aerofoils. From the simulation, overall pressure distribution on these two aerofoils was found. It is clear that there was less negative pressure developed on the upper surface of NACA 4412 aerofoil than the upper surface of NACA 6409 aerofoil. Streamlines that is vector profiles were more attached within the vicinity of NACA 4412 than in NACA 6409 thus creating less wake in the first one.

Finally, the lift to drag ratios for NACA 4412 aerofoil with an angle of attack 0 degree and 5 degree were respectively 3.365 and 5.382. On the other hand, the lift to drag ratios for NACA 6409 aerofoil with an angle of attack 0 degree and 5 degree were respectively 0.39 and 0.66 .

The better aerofoil always has a higher lift to drag ratio when it is compared with other aerofoils. In this case, NACA 4412 exhibited higher lift to drag ration than NACA 6409. So it is obvious that NACA 4412 is best suited for aerodynamic applications than NACA 6409 with higher lift to drag ratio and less wake generation.

\section{CONCLUSIONS}

After successfully completing this simulation based experiment, the decisions were finally confined into the following points.

- $\quad$ Static pressure distribution on these two aerofoils was visualized. It was found that for same angle of attack, NACA 4412 has less negative pressure on the upper surface than NACA 6409.

- Vector profile and wake generation were also found from the simulation. Wake generation is less in NACA 4412 than NACA 6409 for same angle of attack.

- Coefficient of drag and coefficient of lift were found for different angle of attack from the simulation.

- $\quad$ Finally, lift to drag ratio for these two aerofoils were compared to find out the better aerofoil. In this case, NACA 4412 is better than NACA 6409. 


\section{REFERENCES}

[1] A.G Chervonenko, 1991, Effect of attack Angle on the Nonstationary Aerodynamic Characteristics and Flutter Resistance of a Grid of Bent Vibrating Compressor Blades, Ukrainian Academy of Sciences, Plenum Publishing Corporation, Ukraine, Volume 39, No. 10, pp. 78-81.

[2] Bacha WA, Ghaly WS, 2006, Drag Prediction in Transitional Flow over Two-Dimensional Airfoils, Aerospace Sciences Meeting, USA, AIAA 20062048.

[3] Douvi C. Eleni, Tsavalos I. Athanasios and Margaris P. Dionissios, 2012, Evaluation of the Turbulence Models for the Simulation of the Flow over an Aerofoil, Journal of Mechanical Engineering Research, Greece, Volume 4, No.3, pp. 100-111.

[4] Drishtysingh Ramdenee, H. Ibrahim, N.Barka, A.Ilinca, 2013, MODELING OF AERODYNAMIC FLUTTER ON A NACA 4412 AIRFOIL WIND BLADE, International Journal of Simulation and Process Modelling, Inderscience Publishers, Canada, Volume 8, No. 1, pp. 79-87.

[5] Johansen J, 1997, Prediction of Laminar/Turbulent Transition in Airfoil Flows, Journal of Aircraft, Aerospace Research Central, Denmark, Volume 36, No. 4, pp. 731-734.

[6] Launder BE, Spalding DB, 1974, The Numerical Computation of Turbulent Flows, Computer Methods in Applied Mechanics and Engineering, ScienceDirect, UK, Volume 3, No. 2, pp. 269-289.

[7] Mayurkumar Kevadiya, Hemish A. Vadiya, 2013, 2D Analysis of NACA 4412 Airfoil, International Journal of Innovative Research in Science Engineering and Technology, India, Volume 2, No. 5 , pp. 168-1691.

[8] Menter FR, 1994, Two-Equation Eddy-Viscosity Turbulence Models for Engineering Applications, AIAA Journal, USA, Volume 32, No. 8, pp. 15981605.

[9] Mohammad Mashud, Mausumi Ferdous, Shahriar Hossain Omee, 2012, Effect of Spoiler Position on Aerodynamic Characteristics of an Airfoil, International Journal of Mechanical and Mechatronics Engineering, Bangladesh, Volume 12, No. 6.

[10] Ovais Gulzar, S. Gulzar, S. Bhatele, N. Soni, 2014, Impact of Variation in Angle of Attack on NACA 7420 Airfoil in Transonic Compressible Flow Using Spalart-Allamaras Turbulence Model, IJRMET, India, Volume 4, No. 2, pp. 35-39.

[11] S.A. Prince, V. Khodagolian, C. Singh, T.Kokkalis, 2009, Aerodynamic Stall Suppression on Airfoil Sections Using Passive Air-Jet Vortex Generators, AIAA Journal, India, Volume 47, No. 9, pp. 22322242.

[12] Shih TH, Liou WW, Shabbir A, Zhu J, 1995, A New $\mathrm{k}-\varepsilon$ eddy - Viscosity Model for High Reynolds Number Turbulent Flows, National Aeronautics and Space Administration, USA, pp. 1-32.
[13] S.S Benadict Bensiger and N. Prasanth, 2012, Analysis of Bi-Convex Airfoil Using CFD Software at Supersonic and Hypersonic Speed, Elixir International Journal, Elixirpublishers, India, Volume 53, pp. 11695-11698

[14] Sutherland W, 1893, The Viscosity of Gases and Molecular Force, Encyclopaedia of Australian Science, Australia, Volume 36, pp. 507-531.

[15] http://airfoiltools.com/airfoil/naca4digit.

\section{BIOGRAPHIES}

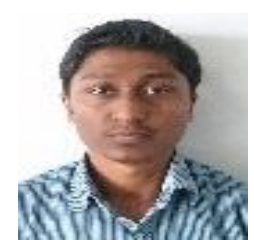

MD. Safayet Hossain was born in 1992 in Chittagong. He is accomplishing BSc in Mechanical Engineering from Chittagong University of Engineering and Technology (CUET) and will complete his course in 2014(expected). His research interests contain Computational Fluid Dynamics, Renewable Energy, Aerodynamics, Heat Transfer and Sustainable Energy.

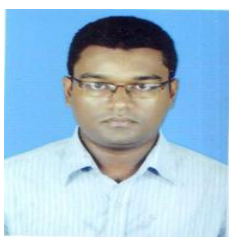

Muhammad Ferdous Raiyan was born in 1990 in Chittagong. He has recently accomplished BSc in Mechanical Engineering from Chittagong University of Engineering and Technology (CUET). His research interests include Computational Fluid Dynamics, Aerodynamics, Heat Transfer, Materials Science, Turbo Machinery and Thermodynamics.

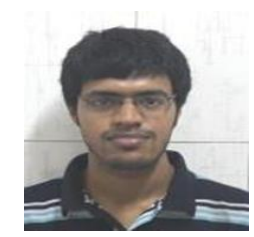

Mohammed Nasir Uddin Akanda was born in 1991 in Chittagong. He is currently accomplishing his $\mathrm{BSc}$ in Electrical and Electronics Engineering from Chittagong University of Engineering and Technology (CUET). His research areas are focused on telecommunication engineering, signal processing, 3 phase induction motor, simulation science and programmable logic controllers (PLC).

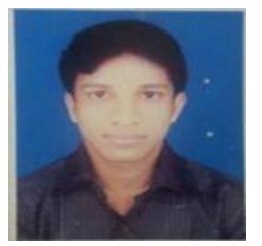

Nahed Hassan Jony was born in 1993 in Chittagong. He is now completing his Bachelor in Mechanical Engineering from Chittagong University of Engineering and Technology (CUET). His research areas are primarily focused on Aeronautical Engineering, Automobile Engineering and Robotics. 